Dominik Kukla

Justyna Szlagowska-Spychalska

Paweł Grzywna

Andrzej Zagórski

\title{
Identyfikacja uszkodzenia zmęczeniowego stopu aluminium 2017 na podstawie pomiarów konduktywności
}

\author{
Conductivity measurements to the identification \\ and location of fatigue failure in the aluminum \\ alloy 2017
}

\section{Streszczenie}

Zaprezentowane badania skupiały się na ocenie możliwości wykorzystania pomiarów konduktywności do identyfikacji i lokalizacji uszkodzenia zmęczeniowego w próbkach ze stopu aluminium 2017. Monitorowanie zmian przewodności w wybranych punktach próbki po kolejnych cyklach obciążeń rozciągających pozwoliło stwierdzić spadek tego parametru w miejscu powstania i rozwoju uszkodzenia, prowadzącego do pęknięcia próbki. Istotne zmiany przewodności występuja w ostatnim etapie zmęczenia i są związane prawdopodobnie z lokalnym odkształceniem plastycznym towarzyszącym rozwojowi pęknięcia dominującego. Testy prowadzono na próbkach wyciętych z blachy walcowanej o grubości 1, 2 i 3 mm poddanych cyklicznym obciążeniom rozciągającym. Pomiar konduktywności realizowany był kilkakrotnie, po zadanej sekwencji cykli, w siedmiu miejscach po obu stronach próbki, co umożliwiło na lokalizację uszkodzenia zmęczeniowego.
Abstract

The research have focused on the use of conductivity measurements to the identification and location of fatigue failure in the aluminum alloy 2017 samples. Monitoring changes in conductivity at selected points of the samples, following subsequent tensile load, have revealed the decrease in conductivity in place of the initiation and development of damage, before the cracks sample. Significant changes in conductivity occur in the last stage and the associated fatigue are likely to be a local plastic deformation accompanying the development of cracks dominant. Tests performed on samples cut from the rolled sheet with a thickness of 1, 2 and $3 \mathrm{~mm}$ treated with a cyclic tensile stress. Conductivity was carried out several times, the key sequence cycles in seven locations on both sides of the sample, allowing the location of fatigue damage

\section{Materiał i metodyka badania}

Badania wykonano na próbkach płaskich, pobranych z blachy walcowanej o grubości 1 , 2 i $3 \mathrm{~mm}$, po obróbce cieplnej i naturalnemu starzeniu. Geometria

Dr inż. Dominik Kukla, dr inż. Paweł Grzywna - PAN, dr inż. Justyna Szlagowska-Spychalska, mgr inż. Andrzej Zagórski - Politechnika Warszawska, i wymiary próbek (rys. 1) zostały zaprojektowane tak, aby możliwy był pomiar konduktywności z zastosowaniem miernika i sondy Sigmatest firmy Ferster.

Parametry wyznaczone w statycznej próbie rozciągania (rys. 2) pozwoliły dobrać zakres amplitudy naprężenia w testach zmęczeniowych od 200 do $300 \mathrm{MPa}$, tak aby obciążenia nie przekroczyły granicy plastyczności i badania miały charakter wysokocyklowy. Badania wykonano na 6 próbkach (po 2 z każdej grubości) o geometrii przedstawionej na rysunku 1. 
Badania wytrzymałościowe (statyczne i dynamiczne) wykonano na maszynie wytrzymałościowej MTS 858, z zakresem siły osiowej +/-25 kN. Do pomiaru przemieszczenia użyto ekstensometru wzdłużnego firmy MTS zamontowanego na próbce specjalnymi uchwytami, jak pokazano na rysunku 3.

Próby zmęczeniowe przeprowadzono dla 11 próbek, każdej z trzech grubości, poddając je obciążeniom cyklicznym w zakresie od 200 do 300 MPa ze skokiem co $10 \mathrm{MPa}$. Przebadano więc po 33 próbki. Podczas badań zmęczeniowych zatrzymywano obciążenie w sekwencjach co 10000 cykli i przy zerowej sile dokonywano pomiarów konduktywności według schematu przedstawionego na rysunku 4a.

Pomiary wykonywano miernikiem konduktywności Sigmatest firmy Ferster w 7 miejscach każdej próbki,

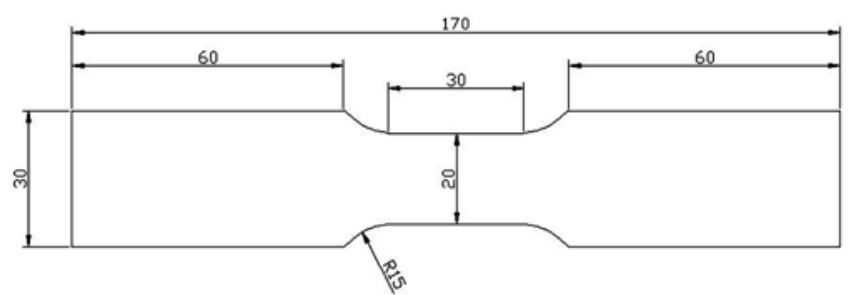

Rys. 1. Geometria i wymiary próbek do badań

Fig. 1. The geometry and dimension of the test samples

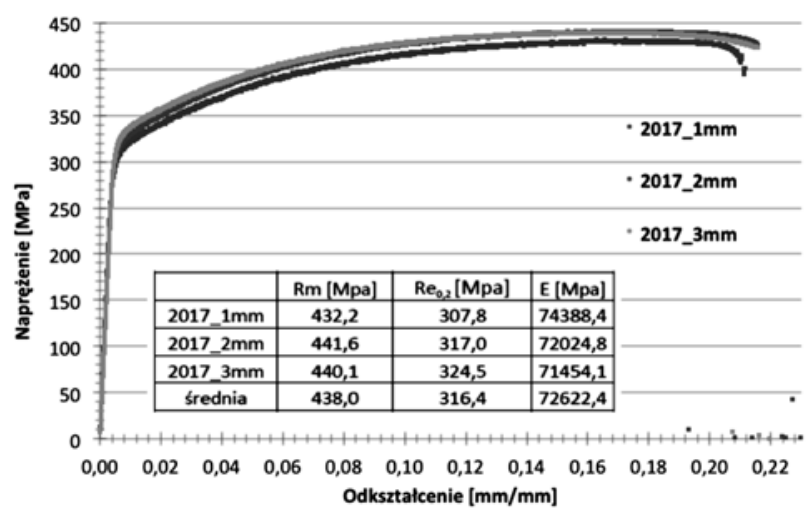

Rys. 2. Wyniki statycznej próby rozciągania próbek ze stopu 2017 Fig. 2. Static tensile test results of alloy samples 2017

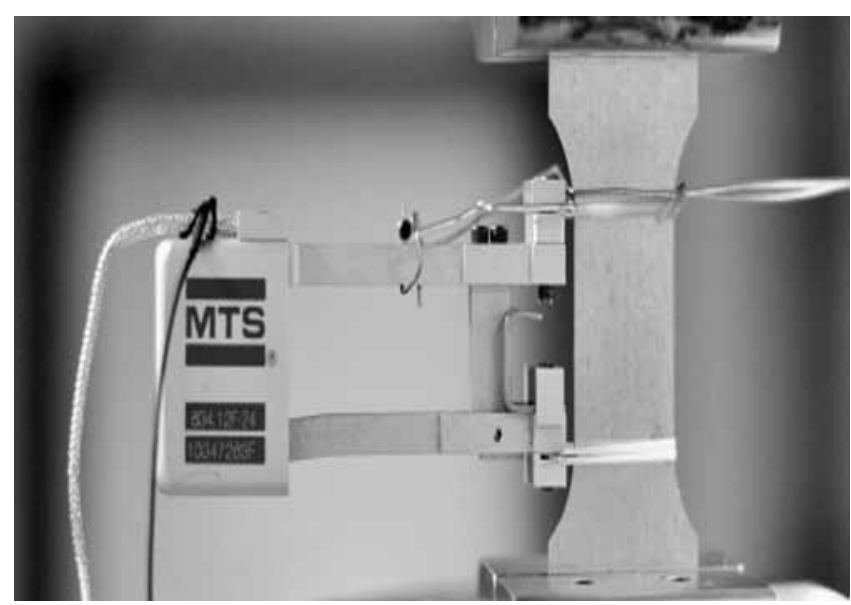

Rys. 3. Próbka w uchwycie maszyny z zamocowanym ekstensometrem Fig. 3. Photo of sample in the machine holder with extensometer według szkicu pokazanego na rysunku 4b. Pomiar w punkcie części chwytowej, oznaczonym „0”, pozwalał uzyskać wartość odniesienia, dla materiału nieuszkodzonego, przy założeniu, że w tym miejscu materiał nie ulega procesowi degradacji zmęczeniowej, co wynika z geometrii próbki. Wykonanie pozostałych 6 pomiarów wynikało z faktu inicjowania uszkodzenia w różnych miejscach próbki, tzn. w obszarze górnej redukcji przekroju (punkty 1, 4), w środku części pomiarowej (punkty 2,5 ) oraz w obszarze dolnej redukcji przekroju (punkty 3, 6). Pomiary wykonano po obu stronach każdej próbki celem wykazania lokalnego spadku konduktywności w miejscu uszkodzenia, a nie wiadomo było, gdzie się ono rozwija.

a)

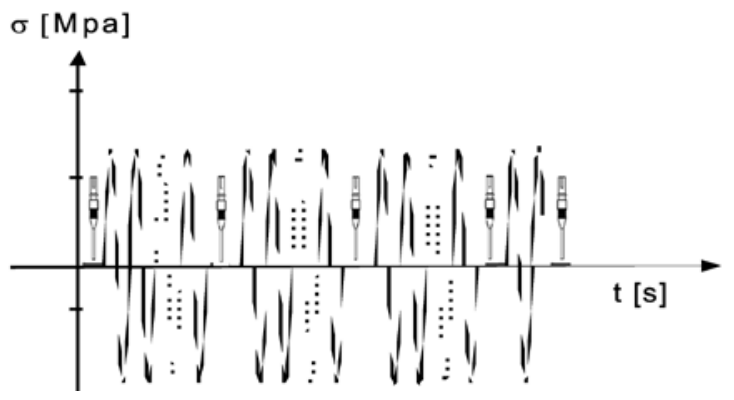

b)

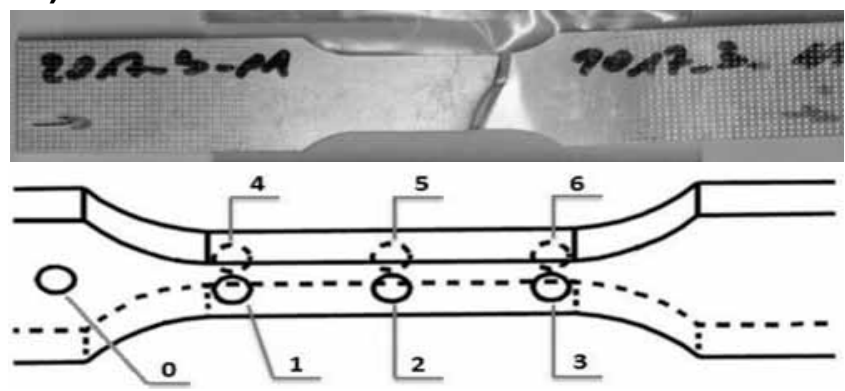

Rys. 4. Szkic procedury wykonania pomiaru konduktywności w teście zmęczeniowym: a) sekwencje pomiaru b) miejsca pomiaru Fig. 4. Outline procedures to measure the conductivity of the fatigue test: a) the measurement sequences b) place of the measurement

\section{Wyniki badań}

Na podstawie wykonanych pomiarów można stwierdzić lokalny spadek konduktywności materiału próbki w końcowym etapie procesu zniszczenia poprzedzającym pęknięcie próbki (rys. 5). Przedstawiono zmiany przewodności mierzonej w tych punktach w kolejnych cyklach obciążenia zmęczeniowego.

Zmiany konduktywności materiału próbki pojawiają się w ostatnim etapie obciążenia, kiedy rozwój pęknięcia dominującego prowadzi do dekohezji. Zmiany te mają charakter lokalny, ale nie powierzchniowy, widoczne są bowiem tylko w jednym punkcie pomiarowym, ale po obu stronach próbki. Efekt ten występuje niezależnie od grubości próbki i wskazuje na to, że proces degradacji zainicjowany lokalnie ma charakter objętościowy. 
1_13_240 ( $f=240 \mathrm{~Hz})$

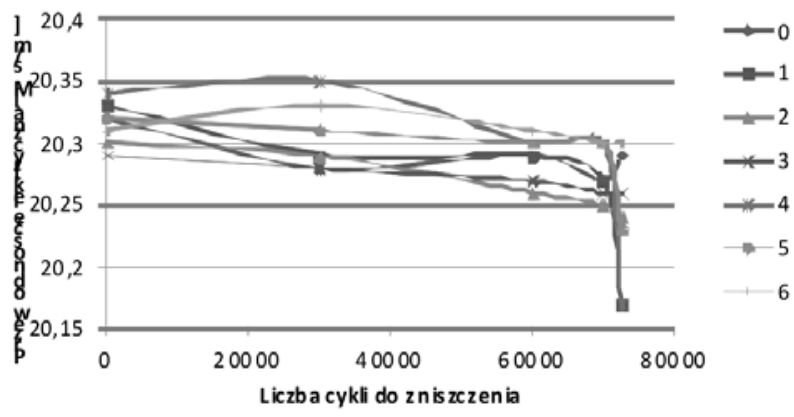

2_09_290 ( $f=240 \mathrm{~Hz})$

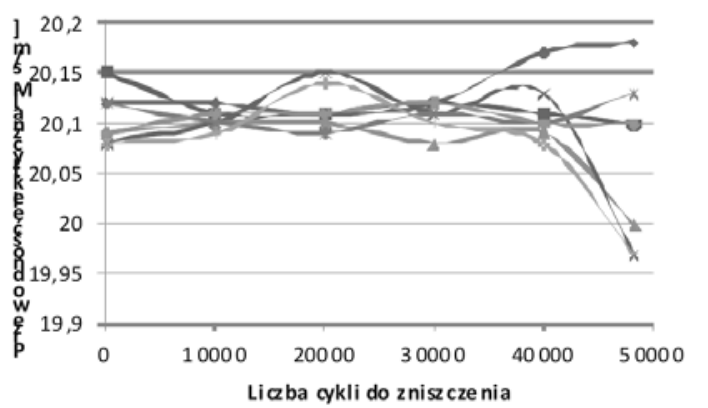

3_09_240 ( $f=240 \mathrm{~Hz})$

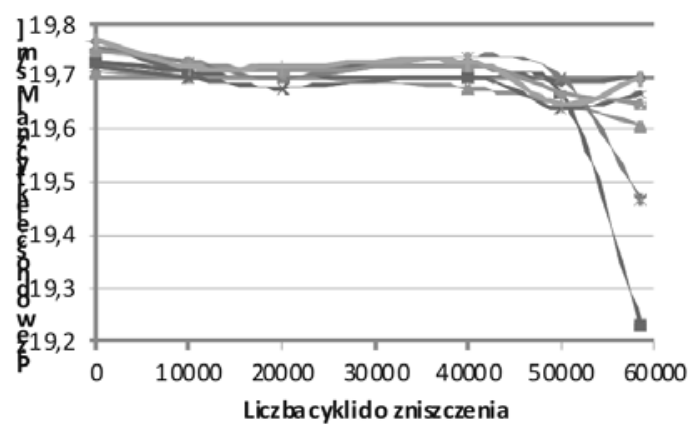

1_13_240 ( $\mathrm{f}=960 \mathrm{~Hz})$

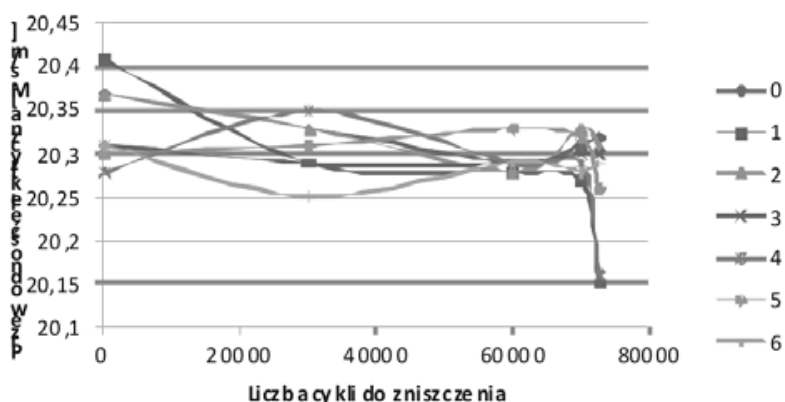

2_09_290 (f $=960 \mathrm{~Hz}$ )

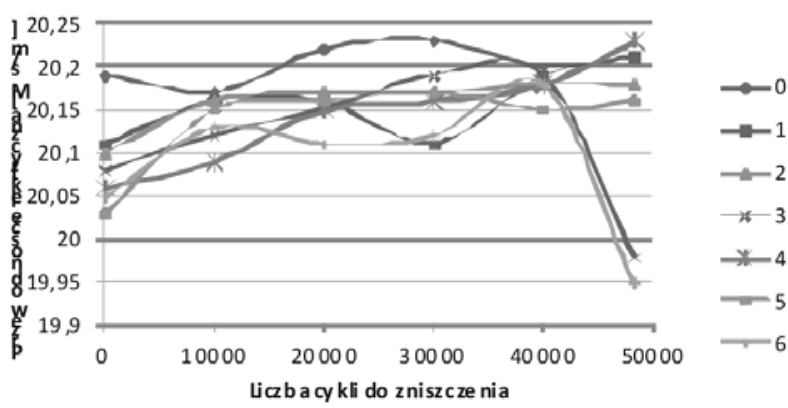

3_09_240 ( $f=960 \mathrm{~Hz})$

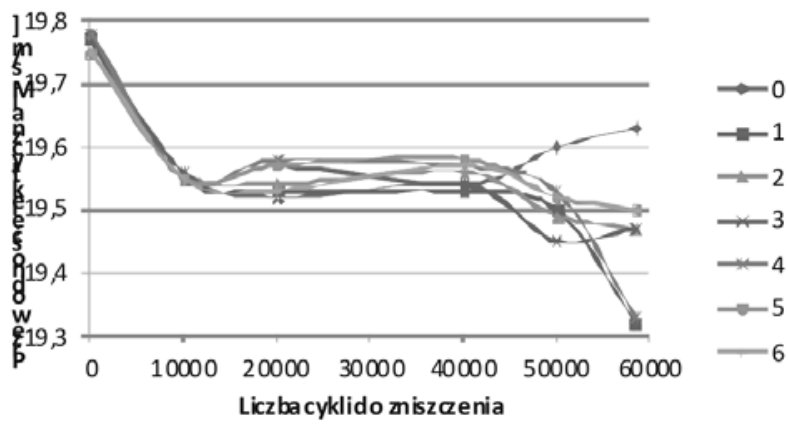

Rys. 5. Wykresy zmienności konduktywności wybranych próbek w kolejnych cyklach obciążenia zmiennego, mierzonej przy częstotliwości 240 oraz $960 \mathrm{MHz}$ dla trzech grubości blach

Fig. 5. Graphs of conductivity variation of selected samples in subsequent cycles of louding, measured at a frequency of 240 and $960 \mathrm{MHz}$ for the three plate thicknesses

\section{Podsumowanie}

Zastosowanie pomiarów konduktywności stopu aluminium 2017 do oceny stopnia degradacji zmęczeniowej doprowadziło do stwierdzenia występowania zależności tego parametru od zmian mikrostrukturalnych towarzyszących procesowi uszkodzenia wywołanego cyklicznym obciążeniem, ale dopiero na etapie rozwoju pęknięcia. Można przypuszczać, że zmiany te maja związek ze zmianami stanu naprężenia próbek wokół karbów strukturalnych wywołanych zmęczeniem. Wskazuje na to fakt, że spadek wartości przewodności rejestrowany w obszarze lokalizacji uszkodzenia próbki jest podobny po obu jej stronach, czyli dotyczy całego przekroju próbki. 


\section{Literatura}

[1] Kukla D.,Dietrich L. ,Ciesielski M.: Ocena stopnia uszkodzenia eksploatacyjnego materiału rurociągu parowego na podstawie analizy zmian właściwości zmęczeniowych i mikrostruktury, VI Międzynarodowe Sympozjum Mechaniki Materiałów i Konstrukcji, Augustów, 30 maja - 2 czerwca 2011.

[2] G. Socha, Experimental investigation of fatigue cracks nucleation, growth and coalescence in structural steel, Int. J. Fatigue, 25, 2003, 139-147.

[3] D. Kukla, L. Dietrich, Z. Kowalewski, P.Grzywna: Ocena Rozwoju Uszkodzeń Zmęczeniowych w Stalach Eksploatowanych w Energetyce - LI Kongres Mechaniki Polskiej Poznań - Sierpień 2011-10-17.
[4] Kukla D.,Dietrich L. ,Ciesielski M.: Ocena Stopnia Uszkodzenia Eksploatacyjnego Materiału Rurociągu Parowego na Podstawie Analizy Zmian Właściwości Zmęczeniowych I Mikrostruktury, Acta Mechanica et Automatica, Vol. 5 No. 3 (2011) s. $55-60$.

[5] Kukla D., Grzywna P., Dietrich L.; The Development Dynamics Of The Located Fatigue Failure In The Porous Silumin 28 Danubia Adria Symposium, Siofok-Hungary, September 2011 materiały konferencyjne, s. 61.

\section{Podziękowanie}

Badania zaprezentowane w artykule zostały sfinansowane przez Narodowe Centrum Nauki w ramach projektu badawczego własnego NN 507217940 "Opracowanie metod diagnozowania odpowiedzialnych elementów konstrukcyjnych statków powietrznych z wykorzystaniem metody prądów wirowych i metody modelowania sygnałów elektromagnetycznych" oraz przez Narodowe Centrum Badań i Rozowju w ramach projektu celowego nr 6 ZR7 2009 C/07352 pt. „Opracowanie technologii i uruchomienie produkcji kokilowych, w tym rdzeniowanych, odlewów ze stopów AlSi7Mg i AlSi10Mg przeznaczonych do budowy nowej generacji osprzętu wyłączników wysokiego napięcia pracujących $w$ środowisku $\mathrm{SF}_{6}$ ".

\section{Wykaz recenzentów artykułów naukowych opublikowanych w miesięczniku naukowo-technicznym Przegląd Spawalnictwa w 2013 roku}

Artykuły w miesięczniku Przegląd Spawalnictwa były recenzowane w 2013 r. przez członków Komitetu Recenzentów w składzie: dipl. Ing. Pawel Baryliszyn, dr inż. Hubert Drzeniek, prof. Nikolaos Gouskos, prof. Jolanta Janczak-Rusch, prof. Andrzej Kolasa, prof. Jerzy Łabanowski, prof. Mirko Sokovic, prof. Edmund Tasak, prof. Johannes Wilden, oraz przez zaproszonych recenzentów zewnętrznych:

Prof. Andrzej Ambroziak

Prof. Alexander I. Balitskii

Prof. Marek Blicharski

Prof. Janusz Ćwiek

Prof. Dariusz Golański

Prof. Leonard Runkiewicz

Prof. Jacek Senkara

Prof. Ryszard Sikora

Prof. Jacek Słania

Prof. Eugeniusz Turyk

Prof. Jasiński Walenty

Prof. Andrzej Winiowski

Prof. Anna Zielińska-Lipiec

Dr hab. inż. Piotr Bała

Dr hab. inż. Tomasz Chady

Dr hab. inż. Jerzy Kaszyński

Dr hab. inż. Jacek Szelążek

Dr inż. Piotr Białucki

Dr inż. Dariusz Fydrych
Dr inż Jacek Haras

Dr inż. Grzegorz Jezierski

Dr inż. Paweł Kołodziejczak

Dr inż Tomasz Kozak

Dr inż. Tomasz Kozieł

Dr inż. Beata Majkowska

Dr inż. Ryszard Pakos

Dr inż. Tomasz Pfeifer

Dr inż. Tomasz Piwowarczyk

Dr inż. Anna Pocica

Dr inż. Grzegorz Rogalski

Dr inż. Adam Sajek

Dr inż. Tomasz Urbański

Dr inż. Aneta Ziewiec

Dipl.-Inf. Hannelore Wessel-Segebade

Mgr inż. Bogdan Piekarczyk

Mgr inż. Jędrzej Hlebowicz

Mgr inż. Marek Lipnicki 